\title{
De Professor de Matemática a Pesquisador em Educação Matemática: uma trajetória*
}

\author{
From Mathematics Teacher to Researcher in Mathematics Education: a \\ history
}

André Luis Trevisan ${ }^{* *}$

\begin{abstract}
Resumo
Consciente que minhas (pré) concepções acerca da Matemática, de ensinar Matemática e, principalmente, de avaliar em Matemática provêm da própria história enquanto estudante e professor em formação, organizei o memorial que aqui apresento e que constituiu parte do capítulo inicial de minha tese de doutorado. Partindo de uma experiência com a utilização de uma prova em fases nas aulas de Matemática, numa tentativa de aproximála de sua perspectiva formativa, deparei-me com uma série de inquietações que me instigaram a interpretar quem sou, o que penso e por que assim penso. Este texto, que retrata parte do caminho trilhado, é resultado desse processo de reflexão, em que me tornei protagonista da minha própria pesquisa, na qual propus-me a investigar minha atuação em sala de aula e em especial minha prática avaliativa, a partir das relações com os vários contextos nos quais encontro-me inserido. Ao publicá-lo, vislumbro instigar outros professores a se tornarem também investigadores de suas práticas.
\end{abstract}

Palavras-chave: Educação Matemática. Avaliação da Aprendizagem Escolar. Avaliação como Prática de Investigação.

\begin{abstract}
Aware that my (pre) conceptions of mathematics, mathematics teaching, and mainly assessment in mathematics come from my own history as a student and as a teacher in training, I organized this memorial which I present here and that constitutes the initial chapter of my doctoral thesis. Starting from an experience with the use of a stage test in Mathematics classes, in an attempt to bring it closer to its formative perspective, I came across a number of concerns that prompted me to interpret who I am, what I believe in, and why I think in a certain way. This text depicts part of the path and is the result of a reflective process, in which I became the protagonist of my own research, proposing to investigate my performance in the classroom and, in particular, my assessment practice, from relations with the various contexts in which I find myself inserted. By publishing it, I glimpse at "instigating" other teachers to become researchers of their own practices too.
\end{abstract}

\footnotetext{
* Embora seja um texto em primeira pessoa, agradeço à minha orientadora de Doutorado, professora Dra. Regina Luzia Corio de Buriasco, além da leitura e sugestões, o compartilhar das experiências aqui relatadas.

** Doutor em Ensino de Ciências e Educação Matemática pela Universidade Estadual de Londrina (UEL). Docente da Universidade Tecnológica Federal do Paraná (UTFPR), câmpus Londrina, Paraná, Brasil. Endereço para correspondência: Av. Brasília, 2051, Cond. Portal das Flores, CEP: 86600-224, Rolândia, PR, Brasil. Email: andrelt@utfpr.edu.br.
} 
Keywords: Mathematics Education. Assessment of School Learning. School Assessment Process as an Investigative Practice.

\section{Começando... pelo começo?}

Apesar dos constantes questionamentos se eu estava certo da minha decisão, sempre manifestei a vontade de ser professor. Não apenas professor, mas um bom professor. Enquanto estudante, seja da Educação Básica e mesmo no Ensino Superior, entendia que ser bom professor era sinônimo de não enrolar a aula, planejá-la, conduzi-la de forma a cumprir o que havia planejado, cumprir o programa, ter autoridade frente aos estudantes, organizar uma prova coerente com as aulas e que contemplasse os pontos importantes da disciplina. Não que isso tudo não seja importante. Mas, no mínimo, não é tão fundamental quanto eu imaginava naquele momento.

Pois bem, frente à escolha em ser professor, muitos dos meus professores diziam que eu tinha potencial para mais, que seria um desperdício (como se, para ser um bom professor, não precisasse muita coisa). Apesar disso, houve também aqueles que me apoiaram em minha decisão, alguns deles tornando-se mais tarde colegas de profissão.

Em 2002, ingressei na graduação, num curso integrado em Física, Matemática e Matemática Aplicada e Computacional em uma universidade pública do interior paulista. Ao final de três semestres deveria fazer uma escolha: optei pelo Bacharelado em Matemática Aplicada e Computacional, mas cursei em concomitância a Licenciatura em Matemática. Certamente essa escolha teve forte influência da paixão desenvolvida pela disciplina de Cálculo Diferencial e Integral I. Embora não reconhecesse naquele momento o potencial pedagógico de instrumentos como mapas conceituais, diário de aulas, projetos de ensino e softwares de visualização, hoje vejo em minha própria prática reflexos dessas metodologias propostas pelas professoras responsáveis pelas aulas da disciplina e que, à época, considerei inovadoras. Ainda no primeiro semestre, encantava-me a ideia de um dia poder atuar como professor de Cálculo e organizar minhas próprias aulas utilizando todos esses recursos.

Lembro-me que muitos colegas bacharéis em Matemática Aplicada e Computacional cursavam esporadicamente disciplinas da Licenciatura, em geral, como enriquecimento curricular, sem necessariamente ter a pretensão de concluir essa habilitação e, muito menos, de tornarem-se professores. Em conversas informais, constatava que a prioridade deles seria atuar em empresas, longe da sala de aula. A Licenciatura seria apenas um quebra-galho: se nada desse certo haveria a opção pela sala de aula. 
No meu caso, sempre foi o contrário: optei pela Matemática Aplicada não porque desejasse atuar como bacharel na área, mas porque enxergava nesse curso mais possibilidades de compreender a que serve e em que se aplica, afinal, a Matemática. Isso me possibilitaria ser um melhor professor. Além disso, a cada semestre, a prática pedagógica dos meus professores bacharéis matemáticos mais me desmotivava a optar pelo bacharelado em Matemática. Eram aulas e mais aulas copiando as demonstrações que escreviam na lousa, e mais tarde memorizadas e reproduzidas nas provas. As disciplinas do curso também não atendiam minha necessidade de enxergar em que se aplica a Matemática.

Embora sempre participasse de oficinas, eventos, simpósios que aconteciam na Faculdade de Educação, habitat dos professores das disciplinas pedagógicas, acreditava que a opção só pela Licenciatura não daria conta da Matemática que ansiava por aprender. Ainda que essa fosse minha visão como estudante de graduação, arrisco-me a dizer que minha opinião não mudou muito.

Enfim, ambas as habilitações foram finalizadas em quatro anos. Era chegado o fim da graduação, e o mestrado era condição sine qua non na busca da carreira como professor universitário. Mas em qual área? Enfim, eu não poderia ficar nessa dúvida eterna entre a Matemática Aplicada e a Educação Matemática. Naquele momento, optar pela Educação Matemática implicaria deixar para trás a possibilidade de atuar em disciplinas matemáticas, para vislumbrar um futuro como professor de Didática e Metodologia de Ensino. Afinal, eram assim que se apresentavam os editais para concursos públicos na carreira universitária naquele momento e isso era o que eu almejava. Por outro lado, na escolha pela Matemática Aplicada não caberiam discussões acerca de práticas pedagógicas, recursos didáticos e muito menos o que seria aprender Matemática.

Optei pelo mestrado em Matemática Aplicada, na mesma instituição em que havia concluído a graduação. Mais uma vez, de certo modo, meu pragmatismo falou mais alto: não era admissível, na época, falar em Educação Matemática sem antes ter posto o pé em uma sala de aula. Para mim, o estágio obrigatório da graduação e os três anos atuando em cursinho não eram suficientes, haja vista que se tratava de uma realidade recortada, uma prática em momentos pontuais. Sentia necessidade de alguma experiência em uma sala de aula de verdade, senão correria o risco de tornar-me algum tipo de professor como aqueles que eu criticava. Já dizia Sácristan (1998, p. 136): "se quer saber o que é verdadeiramente a educação, conviria muito mais analisar as práticas nas aulas do que se deter muito no discurso embelezado". No fundo, apesar da opção pela Matemática Aplicada, estar em sala de aula, 
bem como pesquisar práticas oriundas da sala de aula sempre foi meu maior desejo. Mesmo hoje, terminado o Doutorado, (felizmente) esse desejo permanece.

Talvez o fato de ter sido classificado tão lá embaixo na seleção tenha me desmotivado antes mesmo de ingressar no mestrado. Afinal, modéstia a parte, eu era um dos melhores estudantes da graduação. Talvez o fato de ter que encontrar, novamente no mestrado, alguns não tão bons professores da graduação, tenha me desmotivado no início. Talvez não estar mais entre os melhores tenha me desmotivado no durante. Talvez o lado professor e a necessidade da sala de aula de verdade tenham me feito voltar para minha cidade natal, ao final do primeiro ano de mestrado, para aceitar uma proposta de trabalho como professor da Educação Básica. Sim, são muitos talvezes, mas possivelmente cada um deles tenha me influenciado com algum peso naquele momento.

Não abandonei o mestrado, porém distanciei-me fisicamente da instituição na qual o cursava. Já havia concluído as disciplinas e a meu ver, para escrever a dissertação, não necessitava estar presente fisicamente na Universidade. Mal sabia o quanto estar longe do ambiente universitário dificultaria as coisas. Ainda assim, algumas idas esporádicas à instituição ao longo do segundo ano do mestrado possibilitaram-me concluí-lo, mas distanciaram-me da pesquisa e do envolvimento com a Matemática Aplicada.

Estava iniciando (ou apenas tomando mais espaço) meu lado professor. Iniciei o ano de 2007 trabalhando com um quinto e um sexto ano do Ensino Fundamental em uma escola particular. Logo veio o sétimo ano e, em seguida, o Ensino Médio. Seis meses mais tarde, iniciava também a tão almejada carreira enquanto professor do Ensino Superior, em contrato temporário em uma instituição pública estadual, na qual mais tarde viria a cursar o Doutorado.

No ano seguinte, algumas outras aulas, monitorias, outra instituição de Ensino Superior. Pois é, com tantas aulas e em níveis de escolaridade tão variados, senti na pele como era ser um professor de verdade. Em momento algum me arrependo, pois aprendi muito nesse período. Além disso, a atuação na Educação Básica muitas vezes mostrou-se mais gratificante que no Ensino Superior. Apesar de o lado professor ocupar-me quase por completo, ainda assim consegui cursar em 2008, como estudante especial, uma disciplina no programa de PósGraduação em Ensino de Ciências e Educação Matemática, na instituição na qual atuava como professor temporário.

No início de 2009, fui aprovado em concurso público e assumi o cargo de professor efetivo do Ensino Básico, Técnico e Tecnológico da Universidade Tecnológica Federal do Paraná, câmpus Apucarana. O ingresso na UTFPR possibilitou-me manter, por mais alguns 
anos, aquela que se mostrou ser uma paixão: atuar com as turmas de Ensino Médio, existentes na Universidade por conta dos cursos técnicos (no ano de 2012 fui transferido, a pedido, do câmpus Apucarana para o câmpus Londrina; desde então, tenho atuado exclusivamente com disciplinas matemáticas em cursos superiores). Além disso, o lado pesquisador começava a aflorar novamente. Com a carga de aulas bem mais reduzida, sobrava mais tempo para preparar as aulas e voltar a estudar. Nesse ano, cursei várias disciplinas como estudante especial do programa de Pós-Graduação em Ensino de Ciências e Educação Matemática da Universidade Estadual de Londrina (UEL). Dentre elas, "Tópicos de Educação Matemática", ministrada por uma professora que mais tarde viria a se tornar minha orientadora de Doutorado, disciplina essa que propiciou um ambiente de leituras e estudos na área de Educação Matemática.

Naquele momento, algumas das minhas reflexões eram um tanto limitadas, baseadas apenas em leituras que haviam sido feitas durante a graduação. Penso que cursar a disciplina ampliou minha capacidade de análise crítica, e as discussões realizadas motivaram-me a frequentar, ainda em 2009, os encontros do GEPEMA ${ }^{1}$, Grupo de Estudo e Pesquisa em Educação Matemática e Avaliação. Motivaram-me também a preparar-me para o ingresso como estudante regular no programa, o que aconteceu no início de 2010.

Desde então, ao mesmo tempo em que cursava disciplinas da Pós-Graduação, semanalmente participava dos encontros do GEPEMA, que acontecem às segundas-feiras, no período da manhã (em caráter de estudo, aberto a estudantes de Graduação e Pós-Graduação e professores da Educação Básica) e no período da tarde (em caráter de pesquisa, com os orientandos de Pós-Graduação). Foi nesse espaço que muitos dilemas, inquietações e dúvidas vieram à tona, mas também novos aprendizados.

Enquanto isso, na UTFPR, encabecei algumas ações ainda modestas na tentativa de fomentar pesquisas no âmbito educacional. Durante os anos de 2011 e 2012, por ser um dos poucos docentes no câmpus (senão o único naquele momento) que frequentava um programa Pós-Graduação na área de Ensino, fui convidado a assumir a função de Responsável pelo Departamento de Educação (DEPED). Diferentemente dos Departamentos Acadêmicos da maiorias das universidades, na UTFPR, o DEPED é uma instância que agrega uma equipe bastante eclética composta por pedagogos, psicólogos, assistentes sociais e enfermeiros que, juntos, buscam delinear ações visando, entre outros, "propor melhorias no desenvolvimento

\footnotetext{
${ }^{1}$ http://www.uel.br/grupo-estudo/gepema/
} 
do processo ensino-aprendizagem por meio do acompanhamento de desempenho de docentes e discentes" (UTFPR, 2009, Art 46).

Dentre as ações desenvolvidas no câmpus Apucarana, naquele momento, destaco duas. No segundo semestre de 2011, juntamente com duas pedagogas, organizamos um projeto intitulado "Oficina de Avaliação - a difícil tarefa de avaliar com qualidade". Por meio dele, propusemos organizar, em oito encontros quinzenais de uma hora e meia, um espaço de reflexão a respeito dos instrumentos de avaliação utilizados por professores das diversas áreas do conhecimento da instituição. Conforme apontaram Barboza, Trevisan e Amaral (2012), os encontros possibilitaram tanto à equipe proponente, quanto aos docentes participantes, explicitar suas angústias e realizar confissões a respeito de como concebiam a avaliação.

Uma segunda ação foi a aprovação, em edital de pesquisa da Fundação Araucária, do projeto de pesquisa “Avaliação da aprendizagem em ensino de Ciências da Natureza e Matemática”. Desde do segundo semestre de 2012, um grupo de discussão e reflexão por mim coordenado e formado por duas pedagogas, uma técnica em assuntos educacionais mestre em Ensino de Ciências e uma professora da área de Ensino de Química tem se reunido semanalmente para realizar uma leitura da avaliação da aprendizagem no âmbito do ensino de Ciências da Natureza e da Matemática, ampliando a compreensão dessa temática a partir da concepção de vários autores, como também, fazer um estudo dos instrumentos disponíveis visando ações de formação. Essa aprovação representou para o grupo uma grande vitória naquele momento, visto que representava sua inserção na pesquisa na área educacional.

Certamente minhas crenças a respeito de ensino e aprendizagem mudaram, depois de novas leituras e novas experiências. Não sou capaz de explicitar quais eram, mas certamente provinham da minha própria experiência enquanto estudante. Hoje entendo o conhecimento como algo que não seja simplesmente transmitido ou descoberto, mas construído por meio de e nas interações sociais, a partir de situações que possibilitem aos estudantes produzir algum significado àquilo que lhes é proposto. E, como não poderia deixar de ser, modificaram-se também minhas crenças a respeito de avaliação, objeto central da minha pesquisa de doutorado.

\section{A proposta indecente}

Ao cursar a disciplina "Tópicos em Educação Matemática" no primeiro semestre de 2009, deparei-me com o texto "A avaliação como Prática de Investigação e Análise da Produção Escrita em Matemática". Ao referir-se à avaliação praticada em sala de aula, os 
autores apresentavam-na tomada, muitas vezes, como "instrumento de punição que provoca medo, angústia, rejeição" e como "filtro de classificação em um processo de exclusão" (VIOLA DOS SANTOS; BURIASCO; CIANI, 2008, p. 36). Incomodava-me naquele momento o caráter tão pessimista presente nas palavras dos autores. Afinal, que tanto mal poderia causar na vida do estudante uma simples provinha? Uma boa nota seria consequência do empenho daquele estudante: ele havia prestado atenção às aulas, desenvolvido as tarefas que o professor havia solicitado, havia se preparado para a prova. Que mal poderia haver nisso? Em contrapartida, uma nota baixa indicava que, de algum modo, aquele estudante era relapso, não prestava atenção às aulas, não desenvolvia as tarefas propostas, não estudava para as provas. Simples, não?

Participar de um grupo de pesquisa em que se discute avaliação certamente mostrou-se (e ainda tem se mostrado) um grande desafio. Hoje entendo que tratar dessa temática não é uma tarefa simples. Talvez eu tenha me espelhado muito em mim mesmo. Afinal, em toda minha trajetória escolar sempre fiz provas e sempre fui bem, pois sempre estudava. Por que as coisas deveriam mudar? Se havia funcionado comigo, por que não haveria de funcionar com os outros?

Segundo Barlow (2006, p. 161), "na recepção intelectual dos mesmos conhecimentos, a reação afetiva às mesmas situações varia infinitamente de um indivíduo a outro". De fato, minha reação afetiva à avaliação naquele momento, restrita a minha própria experiência escolar enquanto receptor de conhecimentos, era bastante limitada.

Mergulhar nas leituras a respeito dessa temática tão complexa exigiu (e continua exigindo) um esforço constante para desprender-me de alguns preconceitos. Não é nada fácil, principalmente quando se está, no seu dia a dia, em círculos de conversas entre professores nos quais o discurso enfatiza, como justificativa do baixo rendimento, a falta de comprometimento e a falta de base observada em estudantes tanto da Educação Básica quanto em ingressantes nos cursos superiores. É comum encontrarmos entre os professores aqueles que oferecem aulas de revisão nas primeiras semanas de aula, ou até mesmo cursos de nivelamento, nos quais são retomados conteúdos matemáticos oriundos dos níveis anteriores de escolaridade (como se os estudantes, anteriormente, já houvessem tido alguma oportunidade para aprendê-los), como forma de buscar uma solução para essa situação. Entretanto, mesmo depois destes esforços, é visível sua decepção e sua frustração, já que parte considerável dos estudantes apresenta, ainda, desempenho insuficiente nas provas. Crentes que nada mais possa ser feito, muitas vezes não reorganizam suas práticas pedagógicas e, em 
consequência, não oportunizam aos seus estudantes meios para a compreensão e superação das dificuldades.

Afinal, para muitos, cabe ao professor

\begin{abstract}
'ensinar o conteúdo' já previsto em um programa, ao aluno, 'prestar atenção' e, em seguida, fazer uma série de exercícios para 'treinar' o que 'aprendeu', mesmo que, muitas vezes, não reconheça a importância do conteúdo; ao final do bimestre, o aluno faz uma prova, a qual, quase sempre, contém exercícios análogos aos já resolvidos em suas tarefas e, então, o professor atribui alguma nota a essa prova (FERREIRA, 2009, p. 14).
\end{abstract}

Nesse trecho, Ferreira (2009) elenca um emaranhado de ritos presentes no cotidiano escolar: é preciso cumprir o programa; fazer exercícios para aprender o conteúdo; é preciso fazer uma prova ao final do bimestre; é preciso atribuir alguma nota a essa prova. Podemos extrapolar: primeiro o professor ensina o conteúdo, e depois aplica a prova; a prova precisa ser feita individualmente; as questões da prova devem ser guardadas a sete chaves, quem presta atenção às aulas apresenta boas notas, mas quem não presta...

Enfim, nessa visão conservadora de avaliação, se algo dá errado, a culpa é, ou do professor, ou do aluno. Embora essa visão de culpabilidade esteja muito presente no contexto escolar, esse fenômeno de insucesso "raramente é visto enquanto relação, do ponto de vista interno da adequação ou inadequação do modo de ensinar aos modos de aprender dos alunos" (ROLDÃO, 2001, p. 130). Para essa autora, é necessária uma reapreciação das práticas que circunscrevem todo o contexto escolar:

\footnotetext{
Como se ensina? Que faz o professor para ensinar - fazer aprender - Aqueles alunos? Como organiza o ensino e não apenas os conteúdos de um programa? Que sabe ou que estuda sobre a construção e apropriação do conhecimento? Que decisões toma, com quem e com que análise prévia de cada situação?
}

A autora fala da necessidade de uma ruptura nos pressupostos, nos princípios e nas práticas da escola enquanto organização curricular. Entendo que essa dinâmica de reconceitualização da escola perpassa um profundo repensar da avaliação que hoje se pratica na escola, na busca de tomá-la como um projeto intencional e planejado no cotidiano das aulas.

Porém, diversas vezes questionei-me como fazer: como tornar a avaliação uma prática de investigação, que possibilite ao professor interpretar, incluir, regular e mediar os processos de ensino e de aprendizagem? Barlow (2006, p. 165) nos dá uma pista: é necessário matar o imaginário avaliador, pondo em questão e rejeitando os mitos e os ritos vetores de falsas aparências; mas, também, é preciso saber ressuscitá-lo, conservando ou recriando "aquilo que é portador de sentido e rico de eficácia potencial". 
Por que não me tornar, então, cobaia de mim mesmo, matar meu próprio imaginário avaliador? Quais seriam os mitos que eu trazia "nas minhas tripas"2 e os ritos que eu praticava enquanto professor-avaliador? "O mito nos faz considerar uma coisa como verdadeira, porque ela é dita desde sempre [...] e o rito nos faz considerar como bom aquilo que é feito desde sempre" (BARLOW, 2006, p. vii). Que mitos e ritos circunscreviam meu ato de avaliar? Que coisas eram consideradas verdadeiras para mim nesse contexto?

Pois bem, naquele momento minha concepção de avaliação resumia-se em fazer prova. Portanto, reconceitualizar a avaliação implicaria, basicamente, modificar o instrumento de avaliação (a prova). Mas não muito... afinal, nas aulas de Matemática, a prova escrita é vista como algo sacrossanto e recoberto por uma aura de glória.

A ideia de experimentar a prova escrita como instrumento de avaliação em minhas aulas, em moldes parecidos com a prova em duas fases, surgiu no início do ano de 2010, quando ingressei no doutorado. Trata-se de uma prova escrita realizada em dois momentos: uma primeira etapa na sala de aula, com tempo limitado, e uma segunda fase, num tempo maior, em geral, a ser feita em casa. Para De Lange (1987), a prova em duas fases oportuniza aos estudantes refletir a respeito de seu próprio trabalho: depois de resolvida pela primeira vez na escola, a prova é corrigida e comentada pelo professor e, posteriormente, devolvida ao estudante para o trabalho adicional em casa.

Entretanto, diferentemente dela, a proposta feita por minha orientadora (que, à guisa de desafio, chamou de proposta indecente) foi elaborar uma prova que contemplasse todo o conteúdo anual de uma das disciplinas que eu ministraria naquele ano, e com todas as fases sendo feitas em sala de aula. Pensei: como assim, uma prova envolvendo todo o conteúdo, e que, ainda por cima, os estudantes teriam acesso no primeiro dia de aula? Aquilo ia contra meus princípios. Quem iria prestar atenção às minhas aulas, já que todos conheceriam a prova logo no início? Sem a prova, qual seria minha moeda de troca (ameaça) com as turmas?

Mas, nas palavras de Barlow (2006), era necessário matar meu imaginário avaliador. Aceitei então o desafio, com uma condição: elaborei a prova contemplando apenas conteúdos programados para o primeiro semestre. Naquele momento, parecia muito arriscado envolver o conteúdo anual. Além disso, caso não desse certo, teria ainda o segundo semestre para pôr as coisas nos eixos. Como forma de diferenciar esse instrumento da prova em duas fases, referiremo-nos a ele simplesmente como prova em fases.

\footnotetext{
${ }^{2}$ Expressão utilizada por Buriasco (minha orientadora de doutorado) ao referir-se às preconcepções que temos a respeito de alguma temática, e das quais, muitas vezes, não conseguimos nos desprender como desejaríamos.
} 
Em princípio, pensamos essa proposta apenas como um piloto. A partir da leitura de alguns relatos que descreviam experiências similares àquela que pretendia desenvolver e sem muito (ou sem nenhum!) embasamento teórico, selecionei um rol de questõest típicas, provenientes de livros didáticos e provas aplicadas em anos anteriores, e parti para o campo.

Utilizei esse instrumento na disciplina de Matemática das três turmas com as quais atuei no ano de 2010: segundo, terceiro e quarto anos do Curso de Educação Profissional Técnica de Nível Médio Integrado em Vestuário, da UTFPR, câmpus Apucarana. Embora fosse um piloto, alguns procedimentos foram necessários. Organizei um diário de campo ${ }^{3}$ que incluía uma descrição, bem como minhas percepções ${ }^{4}$ ao longo do processo. A fim de acompanhar as resoluções, fiz cópia das provas de todos os estudantes, a partir da segunda fase da prova.

Organizei a prova para ser resolvida em seis fases ${ }^{5}$, incluindo questões que contemplavam todo o conteúdo programado para o semestre. Não havia indicação de quais delas deveriam ser resolvidas a cada etapa, de modo que os próprios estudantes deveriam ser capazes de saber qual resolver, podendo alterar as resoluções, nas etapas subsequentes, sempre que julgassem necessário. Receberam-na logo no primeiro dia de aula e tiveram um tempo de 25 minutos para conhecê-la. Minha intenção não era necessariamente que resolvessem as questões nesse primeiro momento, mas apenas soubessem como seria a prova naquele semestre (mesmo porque as questões contemplavam conteúdos que ainda seriam explorados em aula). Ao final desse tempo, devolveram-na, e assim se sucedeu nas outras cinco fases, porém num tempo maior (100 minutos). Assim, à medida que o semestre passava e os conteúdos eram trabalhados na aula, os alunos teriam condições de resolver as questões da prova. Essas seriam apenas pontuadas ao final da terceira e da sexta fases, para atribuição das notas do primeiro e segundo bimestres, respectivamente, por exigência da Instituição. Embora soubessem de sua nota parcial, os estudantes não tiveram acesso aos critérios de correção antes do final da sexta fase.

Além disso, ao final da terceira fase, ao lado de cada resolução, independentemente de estar correta ou incorreta, apresentei um questionamento, buscando instigar os estudantes a

\footnotetext{
${ }^{3}$ Denomino diário de campo o conjunto de anotações tomadas ao longo das aulas em que os estudantes resolviam a prova em fases.

${ }^{4}$ O termo percepções caracteriza impressões de caráter pessoal (Por exemplo, "ao fím da prova, sinto-me frustrado com o fato de muitos estudantes entregarem a prova muito antes do tempo previsto para seu término").

${ }^{5}$ A escolha das seis fases justifica-se por, usualmente, se utilizar como instrumentos de avaliação duas provas escritas realizadas a cada bimestre e mais uma prova de recuperação, totalizando seis provas ao longo de um semestre.
} 
refletirem acerca das resoluções que haviam apresentado até aquele momento. Esse foi o único feedback que tiveram de sua prova.

À medida que o semestre passava e passavam também as fases da prova, inquietavame a sensação das coisas estarem dando errado. Na condição de professor, minha expectativa era que, ao possibilitar aos estudantes alterar suas resoluções, nas várias fases da prova, esta de fato se efetivaria. Também imaginava que, de algum modo, os estudantes comprariam a ideia, dedicando-se com afinco à resolução das questões. Sentia-me extremamente frustrado, pois, ao contrário daquilo que esperava, mostravam-se descontentes com a proposta, e não davam o retorno que eu havia idealizado. Passavam-se as fases da prova, muitas questões em muitas provas permaneciam em branco, mesmo eu tendo trabalhado com as turmas o conteúdo necessário para sua resolução.

Apenas mais tarde, e à medida que a pesquisa desenrolava-se, eu perceberia as potencialidades do instrumento. Assim, por exemplo, a "possibilidade de fazer e refazer as questões da prova quantas vezes fossem necessárias, oportunidade genuína quando se fala em feedback num contexto de avaliação formativa" (TREVISAN, 2013, p.137), mostrou-se bastante limitada naquele momento. Estudos desenvolvidos no interior do GEPEMA, alguns ainda em andamento, tem apontado a prova em fases como um instrumento que vai ao encontro de uma avaliação que seja, para o professor, uma prática de investigação e, para o estudante, uma oportunidade de aprendizagem.

Naquele momento, porém, chegar ao final da sexta fase da prova foi um alívio! Poderia, enfim, voltar a aplicar provas como fazia até então. Mal sabia eu que (felizmente!) isso nunca mais aconteceria.

Apesar da minha resistência em tomar a prova em fases como objeto de estudo para uma pesquisa, mostrou-se bastante prazeroso organizar o relato dessa proposta piloto, o que deu origem a um artigo científico (TREVISAN; BURIASCO, 2011). Apresentar esse relato e compartilhar a experiência com outros pesquisadores causou-me novos ânimos e deu novos rumos ao trabalho; esse evento pode ser considerado como um divisor de águas para o delineamento de uma pesquisa que deu origem à minha tese de doutorado.

Hoje enxergo nesse episódio aquilo que Garnica (2001, p. 8) denomina "maturidade vivencial", necessária a uma incursão mais plena na pesquisa qualitativa, pois

é o contato com os pares, o conhecimento das articulações das e nas instituições, o tráfego pelo mundo acadêmico em suas múltiplas perspectivas, as concepções que se formam com a compreensão de textos, contextos e teorias, o experienciar de perspectivas que não são, em princípio, 'nossas', mas que a nós se oferecem como símbolos ávidos por serem interpretados. [...] Essa gama de diferentes fatores subsidiam e enriquecem a pesquisa realizada na vertente qualitativa, dado, 
principalmente, estar nas mãos do pesquisador - e não de um método pré-definido a responsabilidade pela apreensão dos conhecimentos que - espera-se - possam ser compartilhados, tornados públicos.

Para esse autor, incluir-se consciente e comprometidamente numa linha de pesquisa (no caso, qualitativa) é "abrir-se ao fato de que essa inclusão, ela própria, já é, por si, elemento essencial para essa maturação em ação" (GARNICA, 2001, p. 8). Assim, a maturidade do pesquisador e da pesquisa são fatores que se retroalimentam e a pesquisa acaba por constituir-se ao longo dela própria. Compartilhar com outros pesquisadores minhas angústias e frustrações foi fundamental para olhar com outros olhos a experiência.

\section{0 emergir de um problema de pesquisa}

Entendemos que, no cotidiano da sala de aula usual, na qual vivenciamos a experiência com a utilização da prova em fases, foi possível identificar um contexto propício à realização de uma investigação de caráter qualitativo, a partir da análise sistemática dos dados já recolhidos.

Após ter passado algum tempo no campo, [o investigador] encontra-se em muito melhor situação para discutir quais os seus planos e o que poderá tirar de seus dados. Pode, então, discutir alguns temas emergentes. Evidentemente que não terá certeza sobre a evolução do estudo, nem acerca da forma como irá efectuá-lo (BOGDAN; BIKLEN, 1994, p. 106).

Segundo esses autores, os investigadores qualitativos recolhem dados "ricos em pormenores descritivos relativamente a pessoas, locais e conversas [...] em função de um contacto aprofundado com indivíduos, nos seus contextos ecológicos naturais”. Além disso, ainda que venham a "seleccionar questões específicas à medida que recolhem dados, a abordagem à investigação não é feita com o objectivo de responder a questões prévias ou de testar hipóteses" (BOGDAN; BIKLEN, 1994, p. 16).

Assim, o

investigador qualitativo evita iniciar um estudo com hipóteses previamente formuladas para testar questões específicas para 'responder', defendendo que a formulação das questões deve ser resultante da recolha de dados e não efectuada $a$ priori. É o próprio estudo que estrutura a investigação, não idéias preconcebidas ou um plano prévio detalhado (BOGDAN; BIKLEN, 1994, p. 106).

Ao encontro dessas ideias, Garnica (2001, p. 6) aponta que é

o cotidiano que faz aflorarem as perplexidades que levam às perguntas sobre o mundo que, por sua vez, pedem por modos de ação que permitam a compreensão que, finalmente, são carregadas de volta à cotidianidade, num ciclo contínuo e interminável. 
A abordagem à investigação não foi feita com o objetivo de responder a questões prévias ou testar hipóteses. Ao contrário disso, o olhar enquanto investigador, explicitado por meio da formulação e reformulação da questão de investigação, resultou da recolha de dados obtidos a partir da experiência com a utilização da prova em fases como instrumento de avaliação e também numa perspectiva de refletir a respeito da avaliação como uma prática de investigação. Na condição de pesquisador numa busca constante em incorporar a perspectiva qualitativa, tornei-me mais reflexivo e passei a ter menos certezas das coisas (BOGDAN; BIKLEN, 1994, p. 285).

Borba e Araújo (2004, p. 27) lembram-nos que o processo de construção da pesquisa é, "na maioria das vezes, um longo caminho, cheio de idas e vindas, mudanças de rumos, retrocessos". Esse design da pesquisa foi sendo construído à medida que a própria pesquisa desenvolveu-se. Não podemos dizer que existiam hipóteses claramente definidas enquanto recolhíamos informações a partir da experiência com a prova em fases, mas ao mesmo tempo não podemos ignorar que, enquanto professor, tinha como expectativa que a experiência desse certo.

Ao elaborar a prova em fases, oportunizando aos estudantes resolvê-las ao longo de um semestre, alterando suas resoluções sempre que julgassem necessário, imaginava que estava tornando a avaliação uma prática de investigação. Porém, ao debruçar-me sobre a literatura e buscar um referencial que sustentasse essa minha prática, pude perceber uma série de falhas tanto na elaboração quanto na implementação do instrumento.

$\mathrm{O}$ apostar todas as fichas na prova em fases enquanto instrumento que promoveria a salvação da avaliação esbarrou na minha própria concepção de avaliação. Para mim, caem como uma luva as palavras de Barlow (2006, p. 165): “a 'virtude' formativa não está no instrumento, mas sim, se assim se pode dizer, no uso que dele fazemos, na utilização das informações produzidas graças a ele". Efetivamente, não posso dizer que fiz o melhor uso possível da prova em fases naquele momento, porém enxergo um enorme aprendizado graças às informações a partir dela produzidas.

O instrumento prova escrita havia sido modificado, porém sua própria estrutura carregava uma visão tradicional de avaliação. Se, por um lado, a experiência pontual de utilização da prova em fases nas turmas em tela não pode ser tomada como uma prática de avaliação formativa (na perspectiva de ser formativa para os estudantes) foi inegável seu potencial formativo para mim, enquanto professor. Aquela que seria então uma experiência piloto tornou-se o objeto central de minha pesquisa. 
Além de repensar o instrumento, ficou evidente a necessidade de repensar a própria prática avaliativa, numa busca constante de completá-la, modificá-la e aperfeiçoá-la (BARLOW, 2006). Ao trazer para mim essa tarefa, numa busca de melhorar meu próprio trabalho enquanto avaliador, reconheci-me não apenas como um investigador da própria prática (segundo Ponte (2002), aquele que estuda não um objeto qualquer, mas certo aspecto da sua prática profissional), mas como alguém que investigou a própria prática avaliativa.

Num processo de repensar minha própria prática avaliativa, o desenhar as experiências vivenciadas enquanto estudante e professor em formação foi o ponto de partida de um processo de interpretar quem sou, o que penso, como penso e por que assim penso, e resultou no memorial que aqui apresentei e que constituiu parte do capítulo inicial de minha tese de doutorado (TREVISAN, 2013).

Presumo que muitos professores, seja em formação inicial ou continuada, deparam-se com inquietações parecidas com as minhas e deixam-se "sucumbir frente ao imobilismo gerado pelo sentimento de um conhecimento insuficiente" (HADJI, 1994, p. 129). Ao publicar este trabalho, minha intenção é de algum modo instigar professores a não olharem suas experiências com olhos de fracasso, mas tomarem-nas como motes para investigar suas próprias práticas.

\section{Agradecimentos}

O autor agradece à Fundação Araucária (Convênio 386/2012) pelo Auxílio Financeiro concedido.

\section{Referências}

BARBOZA, W. de L; TREVISAN, A. L; AMARAL, R. G. do. Oficina de Avaliação: a difícil tarefa de avaliar com qualidade. In: Seminário Nacional de Ensino de Ciências e Tecnologia, 3., 2012, Ponta Grossa. Anais... Ponta Grossa: UTFPR, 2012. p. Disponível em:

<http://www.sinect.com.br/2012/selecionados.php>. Acesso em: 25 ago. 2012.

BARLOW, M. Avaliação escolar: mitos e realidades. Porto Alegre: Artmed, 2006.

BOGDAN, R. C.; BIKLEN, S. K. Investigação qualitativa em educação. Portugal: Ed. Porto, 1994.

BORBA, M. C.; ARAÚJO, J. L. (Org.). Pesquisa Qualitativa em Educação Matemática. Belo Horizonte: Autêntica, 2004.

DE LANGE, J. Mathematics, Insight and Meaning. Utrecht: OW \& OC, 1987. 
FERREIRA, P. E. A. Análise da produção escrita de professores da Educação Básica em questões não-rotineiras de matemática. 2009. 166 f. Dissertação (Mestrado em Ensino de Ciências e Educação Matemática) - Programa de Pós-Graduação em Ensino de Ciências e Educação Matemática, Universidade Estadual de Londrina, Londrina, 2009.

GARNICA, A. V. M. Pesquisa Qualitativa e Educação (Matemática): de regulações, regulamentos, tempos e depoimentos. Mimesis, Bauru, v. 22, n. 1, p. 35-48, 2001. Disponível em: <http://www.educadores.diaadia.pr.gov.br/arquivos/File/2010/artigos_teses/MATEMATICA/Artigo_ Vicente8.pdf >. Acesso em: 2 maio 2012.

HADJI, C. A avaliação, regras do jogo. 4. ed. Portugal: Porto, 1994.

PONTE, J. P. Investigar a nossa própria prática. In: GTI (Org.). Reflectir e investigar sobre a prática profissional. Lisboa: APM, 2002. p. 5-28.

ROLDÃO, M. do C. A Mudança Anunciada da Escola ou um Paradigma de Escola em Ruptura?. In: ALARCÃO, I. (Org.). Escola Reflexiva e Nova Racionalidade. Rio Grande do Sul: ARTMED, 2001. p. $115-134$.

SACRISTÁN, J. G. O currículo: os conteúdos do ensino ou uma análise prática? In: SACRISTÁN. J. G; GÓMEZ, A. L. P. Compreender e transformar o ensino. 4. ed. São Paulo: ArtMed, 1998. p. 119148.

UTFPR. Regimento Interno. Curitiba, 2007.

VIOLA DOS SANTOS, J. R.; BURIASCO, R. L. C. de; CIANI, A. B. A Avaliação como Prática de Investigação e Análise da Produção Escrita em Matemática. Revista de Educação, Campinas, v. 25, p. 35-45, 2008.

TREVISAN, A. L. Prova em fases e um repensar da prática avaliativa em Matemática. 2013. 168 f. Tese (Doutorado em Ensino de Ciências e Educação Matemática) - Programa de Pós-Graduação em Ensino de Ciências e Educação Matemática, Universidade Estadual de Londrina, Londrina, 2013.

TREVISAN, A. L; BURIASCO, R.L.C. de. Algumas reflexões sobre a utilização de um instrumento de avaliação. In: I SEMINÁRIO SOBRE OS IMPACTOS DAS POLÍTICAS EDUCACIONAIS NAS REDES ESCOLARES, 2011, Curitiba. Anais... Curitiba: UFPR, 2011, p. . Disponível em:<http://www.ppgecm.ufpr.br/Site_SIPERE/index.html>. Acesso em: 20 out. 2011.

UTFPR. UTFPR: inovação e geração de tecnologias. Disponível em: <http://www.utfpr.edu.br/ainstituicao>. Acesso em: 21 jul. 2011. 